\title{
Repensar el bien común y el Estado en tiempos de pandemia
}

Hugo Quiroga ${ }^{1}$

\section{¿De qué crisis mundial hablamos?}

La inesperada crisis global del coronavirus, que ha acelerado aún más el temor al futuro, ha trastocado nuestras vidas. El aluvión de incertidumbre, la ausencia de certezas, le proporciona espesor y novedades de última hora a lo que ya se sabía. Los cambios de una nueva época provocados por los avances de la derecha radical, los populismos de rostros variados, de izquierda o de derecha, la xenofobia, aparecen justamente en los quebrantos de la democracia liberal. Crece el antiliberalismo como fuerza política y como clima cultural.

Con el siglo XXI ha nacido una época con señales inquietantes, que resulta a veces difícil de comprender y explicar. Vivimos en una era de volatilidad que genera procesos disruptivos en las formas democráticas y en los sistemas políticos. La pandemia hizo más visibles las disfunciones del orden político liberal. Esas disfunciones remiten a la crisis del sistema de partidos, a la disolución de las identidades políticas masivas, a la fluctuación del voto, a los liderazgos de nuevo tipo -de manera frecuente con rasgos decisionistas o autoritarios-, a las desigualdades persistentes y múltiples, componentes que revelan una fatiga democrática, con degradaciones institucionales.

Asoma hoy lo que tiene la apariencia de un cambio societal sistémico que no se puede vislumbrar tan fácilmente, y que permite intuir que el mundo será otro, distinto, que despliega ahora un nuevo movimiento de interrogantes. Una especie de sociedad pospandémica que supuestamente nos introducirá en una nueva era realmente desconocida, en el orden social, político, económico, cultural. Como es difícil ser contemporáneo con nuestra propia época, sobre todo cuando tenemos por

\footnotetext{
${ }^{1}$ Universidad Nacional de Rosario. Universidad Nacional del Litoral. Contacto: haquiroga@fibertel.com.ar
} 
delante una situación excepcional, no se pretende enunciar un pronóstico precipitado e imprudente, sino en pensar en las incógnitas de las derivaciones que se vienen, una vez finalizada la crisis internacional. La velocidad de los acontecimientos nacionales e internacionales vuelven ardua la tarea de pensar el vértigo.

Paradójicamente, la pandemia ha puesto de manifiesto que la crisis mundial no es solo una crisis de la salud pública, sino también política, en el sentido de una disgregación del orden político y socioeconómico. Esto queda demostrado en la globalización que se debilita, en la fragilidad de la idea de solidaridad, en la crisis financiera que no ha sido resuelta, y en la inexistencia de una organización internacional capaz de actuar a escala global frente al COVID-19. Mientras la disgregación revela la insuficiencia de líderes políticos competentes para gestionar una verdadera crisis mundial, comienzan a levantarse enérgicas voces públicascon la mirada puesta en la comprensión y explicación del presente y de un futuro posible.

Sobresale ante todo, la importancia y gravedad de la crisis sanitaria que puede modificar nuestro futuro. En numerosos países se han otorgado poderes de emergencia al Ejecutivo y de control sobre los ciudadanos, lo que abre necesariamente la tensión entre el derecho a la privacidad, la libertad individual, y el bien común, indispensable para proteger y respetar a los demás, pero que no debería remitir a la idea de comunidad orgánica. En china, Singapur, Corea del Sur, Taiwán se ha implementado el control digital de sus ciudadanos para detener el virus. El parlamento húngaro le otorgó a Viktor Orbán poderes extraordinarios, sin límites temporales y sin control. ¿Estos fenómenos pueden se pueden extender a otros lugares en detrimento de la libertad?

El contexto de emergencia es real. El coronavirus ha puesto al mundo en una situación de tremenda indefensión. En la Argentina el régimen de excepción fue instituido en el marco de las normas previstas en la Constitución Nacional, sin renunciar al Estado de derecho. En estas circunstancias, se le permite al Ejecutivo legislar de manera directa a través de las medidas de emergencia: decretos de necesidad y urgencia, delegación legislativa y veto parcial. Hasta ahora se ha reforzado la autoridad presidencial sin el debido control parlamentario, mediante la Comisión Bicameral creada por ley con esa finalidad, según los dispone la misma Constitución.

No está en cuestión aquí la acertada política presidencial encaminada a resolver la crisis sanitaria. El problema es otro, son los abusos y 
arbitrariedades que puedan surgir de gestionar en un régimen de excepción. La situación de emergencia no lo autoriza ni lo habilita todo. El caso de Hungría sería el mejor ejemplo de los riesgos que pueden acarrearle a la democracia la existencia de estos regímenes. Nosotros estamos muy lejos de eso. No obstante, en los hechos no funciona ni el poder legislativo ni el judicial; y desde 1989 en adelante vivimos en «emergencia permanente» (Quiroga, 2005) y con poderes excepcionales con distintas modalidades según la coyuntura histórica. En ese caso, ¿cuál es la capacidad representativa del parlamento?

Entre sucesos irreparables, cobran notoriedad en esta crisis global las vacilaciones y contradicciones de algunos líderes renuentes a tomar decisiones de mayor calado en situaciones de emergencia, por ejemplo, Donal Trump, Jair Bolsonaro, Manuel López Obrador, Boris Johnson, lo que pone en riesgo la vida y la salud de millones de personas. En esta toma de decisiones no se abre una disyuntiva entre darle prioridad a la pandemia o menoscabar las consecuencias económicas de las medidas restrictivas. Las estrategias de gobierno deben compaginar y conjugar los esfuerzos del Estado por salvar vidas -como prioridad- frente a la severidad de la recesión económica, de la que también hay que ocuparse.

A la vez, esas decisiones no deberían ser exclusivamente nacionales, protectoras de una soberanía absoluta, cuando se trata de una crisis internacional que exige respuestas coordinadas en el orden sanitario y económico, encaminadas a la cooperación y la solidaridad global. Sin embargo, los que están al mando de la lucha contra el coronavirus son los Estados nacionales.

Esta situación de emergencia mundial, genera un temor al vacío, a la pérdida de horizonte, y a la muerte, que adquiere una dimensión pública universal. Lo que está en juego es una respuesta a dos temas trascendentales enlazados entre sí, el derecho a la libertad individual y el régimen de excepción, que exige una mirada teórico-política más amplia.

\section{El bien común o la existencia del otro}

En este contexto de emergencia, es necesario ahondar en dos conceptos políticos centrales del pensamiento político moderno, la idea de bien común y el papel del Estado, que refieren a una cuestión existencial, la muerte. 
La noción de bien común, cuyo origen se encuentra en la antigüedad, ha sido silenciada en las sociedades contemporáneas, cuando es la base de la existencia y desarrollo de las mismas. Hoy, una vasta literatura se propone rescatar y reconfigurar dicho término. Más allá de la dificultad de su definición, algunos autores coinciden en que el bien común está representado por la «existencia del otro»; o también que el deber fundamental es darse cuenta que vivimos «entre otros»; o que es «actuar en común»; o que alude a la «vida en común», a una comunidad política que tiene un carácter conflictivo. En su resignificación el bien común incluye el principio de solidaridad -que funda el Estado de bienestar,razón por la que preserva al aparato productivo del cual dependen los trabajadores y empresas.

Lo que crea la idea de comunidad ${ }^{2}$ política es la integración del otro en su distinción, la idea de «cercanía en la distancia». Es lo que apunta Máximo Cacciari (1997) cuando insiste que la comunidad sólo se constituye entre seres auténticamente distintos, entre el extranjero, el peregrino y el que lo acoge. Sólo hay comunidad con lo distante, con lo distinto, ella no tiene razón de ser entre los idénticos, en este caso únicamente existiría cohabitación. La comunidad política, por tanto, no es un espacio homogéneo, no es la comunidad de un solo pueblo.

Según Bobbio (2003), la distinción entre buen gobierno y mal gobierno es uno de los grandes temas -si no el mayor- que recorre la reflexión política de todos los tiempos. El buen gobierno es el del gobernante que ejerce el poder conforme a la ley, pero la ley es buena solamente si tiene como objetivo el bien común. El mal gobierno, en cambio, no respeta las leyes. Por eso, el autócrata o el tirano siguen la voluntad de su capricho; se valen del poder para perseguir su propio bien o interés. Cabe agregar que, más allá del malestar actual con la democracia a tal punto que hablamos de post-democracia-, el sinónimo más apropiado para ella sería el de buen gobierno.

En la tradición política de las ciudades italianas de la Edad Media y del Renacimiento, el ideal del buen gobierno se identificaba con el gobierno para el bien común, opuesto al interés personal del tirano. En los célebres frescos de Ambrogio Lorenzetti, pintados entre 1337 y 1340 en el Palazzo Pubblico de Siena, hay una representación del bien común, del buen y mal gobierno. Aunque sea evidente que esas pinturas -asevera Skinner (2009)- no constituyen un texto convencional de teoría política,

${ }^{2}$ La raíz cum significa lo que «vincula», lo que «junta», «ir con», «en compañía de». 
resulta obvio que su principal propósito estaba dirigido a transmitir una serie de mensajes políticos. La sección central de esos frescos representaba el régimen político que se llegaría a instaurar si se siguieran exclusivamente los dictados de la santa virtud de la justicia. Lo que Skinner se propone en su texto es reabrir el debate sobre la teoría del gobierno, y sobre el ideal de la vida social y política en ella implícito.

¿Cuál es, entonces, la razón de ser del interés público, del bien común? Veamos las respuestas de un autor moderno del siglo XVIII y de otro contemporáneo del siglo XXI. En la mirada de Paine (1986) un gobierno republicano no es otra cosa que un gobierno establecido y guiado por el interés público, tanto individual como colectivo. Todo gobierno que no actúe bajo el principio de la República (res-publica) no es un buen gobierno. Petrella (1993), por su parte, se interroga acerca de qué es hoy el bien común, y si se puede hablar de una sociedad mundial. Si ésta existiera, ¿se podría hablar del bien común mundial? Sin embargo, sostiene, no se puede reflexionar sobre el bien común, ya sea a escala nacional o mundial, sin la ineluctibilidad de «estar y hacer juntos». El bien común está representado por la existencia del otro. Admitir la existencia del otro, como expresión principal del bien común, es identificar el motor que hará crecer las sociedades humanas en el siglo XXI.

Decíamos que buen gobierno y bien común caminan juntos; están interrelacionados y se retroalimentan. El bien común es el presupuesto y el desarrollo de la sociedad, que se materializa en los derechos humanos. Los derechos fundamentales son los derechos humanos, que se imponen como un modelo de referencia, tanto en el orden normativo como político. El sentido de los derechos humanos está dado por su contenido político. En definitiva, constituyen, una guía para la acción pública. Los derechos humanos son los derechos de todas las personas frente a los gobiernos y son los derechos de todas las personas en sociedad (Quiroga, 2019).

El bien común, pues, se estructura en torno al derecho de todas las personas a un «acceso justo» (mejor diríamos igual) a la alimentación, la vivienda, la energía, la educación, el transporte, la información, a una vida libre de violencia, a la participación democrática y a la expresión artística. El concepto de bien común no significa la existencia de una concepción única de bien común, sino que alude a un encuadre de referencia de los derechos humanos, que son iguales, para todas las personas. Por eso, no es apropiado enunciar el bien común como referencia constitutiva de la democracia, como definición normativa. Pero los bie- 
nes comunes están mejor garantizados e institucionalizados en un orden democrático que en cualquier otro tipo de régimen.

\section{$¡$ Hacia un proteccionismo estatal?}

La función esencial del Estado es tomar decisiones, sin negar el momento de la deliberación, en el corto y en el largo plazo para garantizar el bien común, en base a valores, reglas e instituciones. Pero, el rol principal del Estado es definir estrategias de largo plazo, llevar adelante políticas estructurales, y no agotarse en la política de la inmediatez, del corto plazo. Sin negar los cambios que se han producido en el tiempo y en el espacio, así como en la desterritorialización del poder y de la economía, el Estado nacional mantiene una centralidad que en momentos de crisis severas, como la actual, se hace visible. Todos, ciudadanos y empresas, buscan ayuda, alivio y certidumbre en el ámbito del poder ejecutivo, aún a riesgo de que se restrinjan las libertades individuales. La emergencia puede redefinir los límites entre Estado y sociedad. La ciudadanía tiene que estar muy atenta para controlar a sus gobernantes.

Precisamente, la crisis de la pandemia ha colocado al Estado argentino ante el inevitable desafío de dar protección a la ciudadanía y, al mismo tiempo, cuidar la economía. En esta tremenda circunstancia, el Estado pone al descubierto sus reducidas capacidades estatales -técnicas, de escases de recursos, de fragilidad de los mecanismos de control, a pesar de que el gobierno nacional demostró una rápida y eficaz política sanitaria para prevenir la expansión del coronavirus. Las capacidades estatales son los recursos que dispone el sector público, es decir, el Estado y sus diferentes unidades (Palermo, 1998). El análisis de las capacidades estatales permite mejorar la calidad de las decisiones gubernamentales, y conocer el aparato del Estado en sus diferentes niveles. Permite, en definitiva, mejorar la efectividad de las políticas públicas.

Construir o reconstruir instituciones, exige un conocimiento de las propias capacidades del sector público, en función de la implementación de políticas públicas. Entre las más destacadas encontramos las capacidades políticas, que son habilidades de negociación, y las capacidades técnicas, que revelan claridad de metas y de estrategias de incentivos para realizar reformas o tareas eficientes de gobierno.

Por otra parte, en contextos de emergencia, la democracia adquiere un nuevo relieve y resulta evidente la imposibilidad de reducirla a 
instituciones y procedimientos. Con el aislamiento, se profundiza y extiende la esfera digital, junto a las otras esferas en la que se escinde la sociedad, y se establece una participación activa que no se define necesariamente por los canales tradicionales de la política.

La democracia y el Estado de derecho regulan el espacio público que instituye la vida colectiva. De allí el Estado democrático de derecho. Sin duda, existe una relación circular entre el Estado y sus instituciones y la democracia. Justamente, un buen gobierno democrático depende del desarrollo de políticas públicas adecuadas y satisfactorias. El Estado sostiene la democracia porque es el garante de la primacía de los derechos sobre los poderes y de la provisión de bienes básicos de la sociedad. Es una entidad de naturaleza doble; es fuerza y es ley, escribió Paul Ricoeur (1986). Las dos figuras que representan al Estado son la bestia y el magistrado. El Estado es la fuerza que hace cumplir las decisiones de los poderes públicos y es la entidad que toma decisiones en situaciones de emergencia o en circunstancias extremas. A la vez, en su versión democrática, el Estado se define por el derecho antes que por el poder. El Estado de derecho es la creación de un sistema de previsibilidad que limita los excesos de los gobiernos democráticos y protege a los ciudadanos en el ejercicio de sus libertades fundamentales. Es por eso que el Estado de derecho es el lado razonable del Estado, y esta función no se comprende sin la del abuso del poder. Destruido el Estado de derecho sólo queda el Estado como fuerza, sin límites jurídicos.

Es cierto que el Estado argentino tiene dificultades para organizar y orientar a su comunidad histórica. Estamos haciendo referencia a la relación del Estado democrático con su «comunidad histórica» (Ricoeur, 2001), con el pueblo, es decir, con las metas comunes, con la esperanza de todos y el destino colectivo de esa comunidad. Aludimos al «nosotros» (al deseo de vivir juntos en una comunidad política), a una identidad simbólica que comunica a los ciudadanos con su destino común, que se constituye y mantiene por una actividad propia permanentemente renovada, que es sustancialmente diferente del lenguaje nacionalista de singularidad y homogeneidad.

La crisis sanitaria, con sus consecuencias letales, ha legitimado el cierre de las fronteras nacionales, ${ }^{3}$ la derecha radical y los nacionalismos extremos comienzan a pensar en otros escenarios opuestos a la globalización neoliberal, que ha manifestado sus consecuencias perniciosas. De

${ }^{3}$ En la Argentina, hubo cierre de fronteras entre algunas provincias. 
este modo, se puede acentuar la tendencia al proteccionismo, con efectos negativos en el comercio internacional, que pusieron de manifiesto algunas potencias antes del advenimiento de la pandemia, como ser, los Estados Unidos. Se podría verificar, entonces, una reafirmación de los nacionalismos, que en su versión más extrema adopta la forma de separatismo. La globalización se ha guiado por las reglas del mercado, que creó un mundo interdependiente, pero asimétrico, carente de solidaridad. ¿No habría que marchar, acaso, hacia un nuevo multilateralismo?

\section{A modo de cierre}

En verdad, el coronavirus ha colocado al mundo en un estado de inmensa inseguridad. Ciudadanos confinados con escasa capacidad de defensa, Estados sobrepasados por la falta de infraestructura sanitaria, que estaban mejor preparados para la guerra y la destrucción bélica que para enfrentar un virus mortal que desconoce fronteras. Solo queda como horizonte una estrategia de carácter global por el impacto positivo que puede tener en el futuro de la humanidad. Se le atribuye a Pierre Mendés France la idea de que «gobernar es prever», a lo que añadiría que gobernar es decidir. La noción de gobierno (en el sentido de timonel) remite a la definición de políticas estratégicas a largo plazo del Estado, que ofrecen un rumbo al país, y que una buena gestión se ocupará de implementar. El problema surge cuando las políticas del corto plazo, se imponen en la vida colectiva. Triunfa el cortoplacismo.

El bien común y los derechos humanos deben guiar la intervención internacional para preservar la vida y la libertad, para superar las visiones individualistas y egoístas de algunos Estados y la lógica capitalista; para estar presentes además cuando se apliquen regímenes de emergencia. Cuatro condiciones son, al menos, necesarias: la existencia de un espíritu de solidaridad global, esto es, una ética del bien común; fortalecer la legitimidad de las políticas estatales interconectadas; la reunión de líderes políticos mundialesequilibrados, con capacidad y valor, respetuosos del saber de los otros para orientar su acción; el control de la ciudadanía sobre los que mandan. Esto es lo que hoy nos conmueve y preocupa. 


\section{Referencias bibliográficas}

Bobbio, N. (2003). Teoría general de la politica. Madrid, España: Trotta. Cacciari, M. y Martini, C. (1997). Diálogos sobve la solidaridad. Barcelona, España: Herder.

Paine, T. (1986). Los derechos del hombre. México, México:FCE.

Palermo, V. (1998). Estudios sobve el estado del Estado en Argentina. Documento de Trabajo. Buenos Aires, Argentina: Fundación Carlos Auyero-FREPASO.

Petrella, R. (1997). El bien común. Elogio de la solidaridad. Madrid, España: Temas de Debate.

Quiroga, H. (2019). Introducción. Los derechos humanos y el buen gobierno. En H. Quiroga (Coordinador General) y S. Levín (Coordinadora Académica) et al Defensoría del Pueblo de Santa Fe. Progresos y Desafios de los derechos en la provincia de Santa Fe. Evaluación del Estado de Avance. Rosario, Argentina. Disponible en: https:/ /www.defensoriasantafe.gob.ar/institucionales/area-de-investigacion-y-evaluacion-en-derechos-humanos

Quiroga, H. (2005). La Argentina en emergencia permanente. Buenos Aires, Argentina: Edhasa.

Ricoeur, P. (1986). Politica, sociedad e historicidad. Buenos Aires, Argentina: Docencia.

Ricoeur, P. (2001). Ética y Política. En P. Ricoeur, Del texto a la acción. Buenos Aires, Argentina: FCE.

Skinner, Q. (2009). El artista y la filosofía politica. El Buen Gobierno de Ambrogio Lorenzetti. Madrid, España: Trotta/Fundación Alfonso Martín Escudero. 